\title{
Effects of diets containing vegetable oil on expression of genes involved in highly unsaturated fatty acid biosynthesis in liver of Atlantic salmon (Salmo salar)
}

Xiaozhong Zheng, Douglas R. Tocher*, Cathryn A. Dickson, J.Gordon Bell and Alan J. Teale

Institute of Aquaculture, University of Stirling, Stirling FK9 4LA, Scotland

* To whom correspondence should be addressed at Institute of Aquaculture, University of Stirling, Stirling FK9 4LA, Scotland. Tel.: +44-1786-467996; Fax.: +44-1786-472133.

E-mail: d.r.tocher@stir.ac.uk

Running title: HUFA gene expression in salmon fed vegetable oil

Key words: Atlantic salmon; HUFA; biosynthesis; genes; desaturase; elongase; vegetable oil.

Abbreviations FO, fish oil; HUFA, highly unsaturated fatty acids (carbon chain length $\geq \mathrm{C}_{20}$ with $\geq 3$ double bonds); LO, linseed oil; PCR, polymerase chain reaction. 


\section{Abstract}

Fish are an important dietary source of the long-chain $\mathrm{C}_{20}$ and $\mathrm{C}_{22}$ highly unsaturated fatty acids (HUFA), arachidonate (20:4n-6), eicosapentaenoate (20:5n-3) and docosahexaenoate (22:6n-3), that are crucial to the health of higher vertebrates and that can be beneficial in human diets. $\Delta 5$ and $\Delta 6$ fatty acid desaturases, and fatty acid elongases are critical enzymes in the biosynthetic pathways of HUFA from shorter chain $\mathrm{C}_{18}$ polyunsaturated fatty acids (PUFA) such as linoleic (18:2n-6) and $\alpha$-linolenic (18:3n-3) acids. Recently, full-length cDNAs for fatty acid desaturase and elongase enzymes have been cloned from Atlantic salmon. Functional characterisation of the desaturase revealed n-3 $\Delta 5$ desaturase activity, whereas the elongase had broad substrate specificity for PUFA with a range of chain lengths from $\mathrm{C}_{18}$ to $\mathrm{C}_{22}$. The study described here was primarily focused on the nutritional regulation of genes involved in the HUFA biosynthetic pathway in Atlantic salmon. A feeding trial was performed whereby salmon smolts in seawater pens were fed for 40 weeks on five different diets. The diets consisted of a control diet containing fish oil (FO) and four diets in which the FO was replaced in a graded manner by linseed oil (LO). Specifically, in terms of added oils, the five diets were 100\% FO (FO), 100\%LO (LO100) and FO/LO in ratios of 3:1 (LO25), 1:1 (LO50) and 1:3 (LO75). Fish were sampled at 20 and 40 weeks, and samples of liver were collected for lipid analyses and total RNA extraction. Hepatocytes were also prepared and the activity of the HUFA biosynthetic pathway determined. Expression of fatty acid desaturase and elongase genes was determined by quantitative real time PCR and the ratio of the copy number of the targeted gene against that of $\beta$-actin was calculated. The results showed that after 20 weeks of feeding, desaturase and elongase gene expression in liver was increased in a graded manner by increasing dietary LO. Expression of both genes was positively and negatively correlated with dietary 18:3n-3 and n-3 HUFA, respectively. By 40 weeks of feeding, expression of neither gene showed the same degree of correlation with dietary fatty acid composition. In contrast, activity of the HUFA biosynthetic pathway, which showed some association with diet at 20 weeks, was positively and significantly correlated with dietary LO after 40 weeks of feeding. Elongation activity reflected the overall activity of the HUFA biosynthetic pathway to a greater degree than $\Delta 5$ desaturation activity. The possible mechanisms underlying the observed results and the regulation of the HUFA biosynthetic pathway are discussed. 


\section{Introduction}

Salmonids require polyunsaturated fatty acids (PUFA), 18:3n-3 and 18:2n-6, at a combined level of around $1 \%$ of the diet. At this level, through the processes of desaturation and elongation, they meet the substrate needs for production of the functionally active highly unsaturated fatty acids (HUFA) eicosapentaenoate (20:5n-3), docosahexaenoate (22:6n-3) and arachidonate (20:4n-6) (Sargent et al., 1995, 1999). The fatty acyl desaturase enzyme activities are known to be under nutritional regulation in mammals (Brenner, 1981) and this has also been demonstrated in fish (Tocher et al., 1996; Sargent et al., 2002). There is currently considerable interest in these enzyme activities and the regulation of the HUFA biosynthetic pathways in fish in order to determine the effectiveness with which vegetable oils, rich in $\mathrm{C}_{18}$ PUFA but devoid of n-3HUFA, can replace fish oils in the diets of commercially important cultured fish species including salmon (Sargent et al., 2002). This stems from the fact that, if aquaculture is to continue to expand and supply more of the global demand for fish to replace dwindling food fisheries (Tidwell and Allan, 2002), sustainable alternatives to fish oil, derived from equally pressured industrial fisheries (Barlow, 2000), must be found with plant (vegetable) oils as the prime candidates (Sargent and Tacon, 1999). In previous trials we have shown that replacing fish oil with vegetable oils, including borage, linseed, rapeseed and palm oils, in the diets of Atlantic salmon smolts in seawater resulted in increased activity of the fatty acyl desaturation/elongation pathway in isolated hepatocytes (Tocher et al., 1997, 2002; Bell et al., 2001, 2002). Several other studies have shown that the activity of the hepatocyte fatty acid desaturation/elongation pathway was increased in salmon parr (Bell et al., 1997; Tocher et al., 2000), a range of salmonids in freshwater (Tocher et al., 2001a) and freshwater fish (Tocher et al., 2001b).

Significant progress has been made recently in characterising the desaturases and elongases involved in HUFA synthesis (Tocher et al., 1998). Full length cDNAs for $\Delta 6$ fatty acid desaturases have been isolated from the nematode Caenorhabditis elegans (Napier et al., 1998), rat (Aki et al., 1999), mouse and human (Cho et al., 1999a). Fatty acid $\Delta 5$ desaturase genes have been isolated from C. elegans (Michaelson et al., 1998; Watts and Browse, 1999) and human (Cho et al., 1999b; Leonard et al., 2000a). A fatty acid desaturase has been cloned from zebrafish that has been shown to have both $\Delta 6$ and $\Delta 5$ desaturase activities (Hastings et al., 2001). Initially, less attention was paid to fatty acid elongation, but recently genes specifically involved in the elongation of fatty acids in the HUFA biosynthetic pathway have been cloned and characterised from C. elegans (Beaudoin et al., 2000), the arachidonic acid-producing fungus Motierella alpina (Parker-Barnes et al., 2000), humans (Leonard et al., 2000b), rat (Inagaki et al., 2002) and zebrafish (Agaba et al., 2003). 
Recently, we cloned a salmon cDNA (SalDes) that included an open reading frame (ORF) of 1362 bp specifying a protein of 454 amino acids (Hastings et al., 2004). Functional expression in the yeast, Saccharomyces cerevisiae, showed SalDes is predominantly a $\Delta 5$ desaturase, a key enzyme in the synthesis of 20:5n-3 from 18:3n-3. Similarly, a fatty acid elongase cDNA, SalElo, was isolated that includes an ORF of 888 bp, specifying a protein of 295 amino acids (Hastings et al., 2004). Upon expression in yeast, SalElo showed broad substrate specificity for PUFA with a range of chain lengths with the rank order preference being $\mathrm{C}_{18}>\mathrm{C}_{20}>\mathrm{C}_{22}$. Thus, all fatty acid elongase activities required for the biosynthesis of 22:6n-3 from 18:3n-3 were displayed by this one polypeptide product.

In the study described here, we aimed to test the hypothesis that regulation of the activity of the HUFA biosynthetic pathway by dietary fatty acids in fish liver is mediated to at least some degree by a mechanism including transcriptional control of desaturase and/or elongase gene expression. Salmon smolts were stocked randomly into five seawater pens and, after acclimatization for three weeks, were fed for 40 weeks on diets in which the fish oil (FO) component of their diet was replaced in a graded manner by linseed oil (LO). At two points, 20 and 40 weeks, fish were sampled and liver fatty acid composition, hepatic fatty acyl desaturase and elongase gene expression, and activity of the fatty acid desaturation/elongation pathway in isolated hepatocytes were determined.

\section{Materials and methods}

\subsection{Animals and diets}

Atlantic salmon (Salmo salar) post-smolts were randomly assigned to 5 cages $(5 \mathrm{~m}$ x $5 \mathrm{~m}$; 600 fish per cage), with the mean initial weight across the five cages being $127 \pm 3 \mathrm{~g}$ (range 123 to $130 \mathrm{~g}$ ). The smolts were fed one of five diets, consisting of a control diet containing FO as the only added oil component and four diets in which the FO was replaced in a graded manner by LO. Specifically, the five diets were 100\% FO (FO), 100\% LO (LO100) and FO/LO in ratios of 3:1 (LO25), 1:1 (LO50) and 1:3 (LO75), and were prepared by the Nutreco Aquaculture Research Centre, Stavanger, Norway. The formulation, proximate analyses and fatty acid compositions of the diets $(6 \mathrm{~mm}$ pellet) are shown in Tables 1 and 2. All diets were formulated to satisfy the nutritional requirements of salmonid fish (National Research Council, 1993). The fish were fed the experimental diets to satiation by hand for 40 weeks with the fish sampled twice, at 20 and 40 weeks. At 40 weeks, the final weights of the fish were $1.78 \pm 0.40 \mathrm{~kg}(\mathrm{FO}), 1.89 \pm 0.34 \mathrm{~kg}(\mathrm{LO} 25), 1.90 \pm 0.33 \mathrm{~kg}(\mathrm{LO} 50), 1.87 \pm 0.35 \mathrm{~kg}(\mathrm{LO} 75)$ and 
$1.87 \pm 0.33 \mathrm{~kg}(\mathrm{LO} 100)$ and there were no significant differences among different dietary treatments (ANOVA, $\mathrm{P}=0.1555, \mathrm{n}=87$ ). Fish were not fed during the $24 \mathrm{~h}$ prior to sampling.

\subsection{Lipid extraction and fatty acid analysis}

Intact livers were dissected from 18 fish (pooled into 6 samples of 3 livers each) per dietary treatment at each sampling point and immediately frozen in liquid nitrogen. Total lipid was extracted from livers and diet samples by homogenization in chloroform/methanol $(2: 1, \mathrm{v} / \mathrm{v})$ containing $0.01 \%$ butylated hydroxytoluene (BHT) as antioxidant, basically according to Folch et al. (1957). Fatty acid methyl esters (FAME) were prepared from total lipid by acid-catalyzed transesterification using $2 \mathrm{ml}$ of $1 \%$ $\mathrm{H}_{2} \mathrm{SO}_{4}$ in methanol plus $1 \mathrm{ml}$ toluene as described by Christie (1982) and FAME extracted and purified as described previously (Tocher and Harvie, 1988). FAME were separated and quantified by gas-liquid chromatography (Fisons GC8600, Fisons Ltd., Crawley, U.K.) using a 30m x 0.32 mm capillary column (CP wax 52CB; Chrompak Ltd., London, U.K). Hydrogen was used as carrier gas and temperature programming was from $50^{\circ} \mathrm{C}$ to $180^{\circ} \mathrm{C}$ at $40^{\circ} \mathrm{C} / \mathrm{min}$ and then to $225^{\circ} \mathrm{C}$ at $2^{\circ} \mathrm{C} / \mathrm{min}$. Individual methyl esters were identified by comparison to known standards and by reference to published data (Ackman, 1980).

\subsection{RNA extraction and quantitative-PCR $(Q-P C R)$}

Four liver samples per dietary treatment and time point were collected, frozen immediately in liquid nitrogen and stored at $-80{ }^{\circ} \mathrm{C}$ prior to extraction. Total RNA was isolated from 50-100 ug of liver tissue by the standard TRIzol extraction method (Invitrogen Ltd, Paisley, UK) and recovered in $100 \mathrm{ul}$ molecular biology grade water. In order to remove any possible genomic DNA contamination, the total RNA samples were pre-treated using DNA-free ${ }^{\mathrm{TM}}$ DNase treatment and removal reagents kit (Ambion Inc.,Austin, TX, USA) following the manufacture's protocol. Five ug of total RNA was reverse transcribed into cDNA using M-MLV reverse transcriptase first strand cDNA synthesis kit (Promega UK, Southampton, UK). The expression of fatty acid desaturase and elongase genes in liver tissue from salmon fed diets containing graded levels of linseed oil were studied by quantitative (real time) PCR (Q-PCR). $\beta$-Actin was used as a housekeeping gene for normalising mRNA levels of the target genes. The PCR primers were designed according to the published salmon desaturase (accession no: AF478472), salmon elongase (accession no: AY170327) and salmon $\beta$-actin (accession no: AF012125) cDNA sequences. For the $\Delta 5$ desaturase, the forward primer was 5'-

GTGAATGGGGATCCATAGCA-3', and the reverse primer was 5'-AAACGAACGGACAACCAGA- 
3'. For the elongase, the forward and reverse primers were 5'-TGATTTGTGTTCCAAATGGC-3' and 5'-CTCATGACGGGAACCT CAAT-3', respectively. For $\beta$-actin, 5' -

ACATCAAGGAGAAGCTGTGC -3' and 5'-GACAACGGAACCTCTCGTTA-3' were the forward and reverse primers, respectively. PCR products sizes were 192, 219 and 141bp, respectively. The linearised plasmid DNA containing the target sequence for each gene was quantified to generate a standard curve of known copy number. Amplification of cDNA samples and DNA standards was carried out using the SYBR Green PCR Kit (Qiagen, Crowley, West Sussex, UK) in the following conditions: denaturation for $15 \mathrm{~min}$ at $95{ }^{\circ} \mathrm{C}$ followed by 45 cycles of $15 \mathrm{~s}$ at $94{ }^{\circ} \mathrm{C}, 15 \mathrm{~s}$ at $55^{\circ} \mathrm{C}$ and $30 \mathrm{~s}$ at $72{ }^{\circ} \mathrm{C}$, followed by product melting to check purity of PCR product. Thermal cycling and fluorescence detection were conducted using the Rotor-Gene 3000 system (Corbett Research, Cambridge, UK). The copy number of the target gene in the sample was obtained and the ratio of copy numbers between this gene and $\beta$-actin was calculated.

\subsection{Assay of hepatocyte fatty acyl desaturation/elongation activities}

Fish were killed by a blow to the head and the livers dissected immediately. Enriched hepatocyte preparations were prepared by collagenase treatment and sieving as described in detail previously (Tocher et al., 2003). Five $\mathrm{ml}$ of each hepatocyte suspension were dispensed into a $25 \mathrm{~cm}^{2}$ tissue culture flask and the cells incubated at $20{ }^{\circ} \mathrm{C}$ for $2 \mathrm{~h}$ with $0.3 \mathrm{uCi}(\sim 1 \mathrm{uM})\left[1-{ }^{14} \mathrm{C}\right] 18: 3 \mathrm{n}-3$, added as a complex with fatty acid-free bovine serum albumin (FAF-BSA) in phosphate buffered saline prepared as described previously (Ghioni et al., 1997). After incubation, the cell suspension was transferred to glass conical test tubes and centrifuged at $500 \mathrm{~g}$ for $2 \mathrm{~min}$. The supernatant was discarded and the hepatocyte cell pellet washed twice with $5 \mathrm{ml}$ of ice-cold Hank's balanced salt solution without $\mathrm{Ca}^{2+}$ and $\mathrm{Mg}^{2+}$ (HBSS) with the first wash also containing 1\% FAF-BSA. Total lipid was extracted from the washed cell pellets using ice-cold chloroform/methanol $(2: 1, \mathrm{v} / \mathrm{v})$ containing $0.01 \%(\mathrm{w} / \mathrm{v})$ BHT essentially as described by Folch et al. (1957) and as described in detail previously (Tocher et al., 1988). Total lipid was transmethylated and FAME prepared as described above. The methyl esters were redissolved in $100 \mathrm{ul}$ isohexane containing $0.01 \%$ BHT and applied as $2.5 \mathrm{~cm}$ streaks to TLC plates impregnated by spraying with $2 \mathrm{~g}$ silver nitrate in $20 \mathrm{ml}$ acetonitrile and pre-activated at $110{ }^{\circ} \mathrm{C}$ for $30 \mathrm{~min}$. Plates were fully developed in toluene/acetonitrile (95:5, v/v) (Wilson and Sargent, 1992). Autoradiography was performed with Kodak MR2 film for 6 days at room temperature. Areas of silica containing individual PUFA were scraped into scintillation mini-vials containing $2.5 \mathrm{ml}$ of scintillation

fluid (Ecoscint A, National Diagnostics, Atlanta, Georgia) and radioactivity determined in a TRI- 
CARB 2000CA scintillation counter (United Technologies Packard, U.K.). Results were corrected for counting efficiency and quenching of ${ }^{14} \mathrm{C}$ under exactly these conditions.

\subsection{Protein determination}

Protein concentrations in isolated hepatocyte suspensions were determined according to the method of Lowry et al. (1951) after incubation with $0.4 \mathrm{ml}$ of $0.25 \%(\mathrm{w} / \mathrm{v}) \mathrm{SDS} / 1 \mathrm{M} \mathrm{NaOH}$ for $45 \mathrm{~min}$ at $60^{\circ} \mathrm{C}$.

\subsection{Materials}

$\left[1-{ }^{14} \mathrm{C}\right] 18: 3 \mathrm{n}-3$ (50-55 mCi/mmol) was obtained from NEN (DuPont (U.K.) Ltd., Stevenage, U.K.). HBSS, collagenase (type IV), FAF-BSA, BHT and silver nitrate were obtained from Sigma Chemical Co. (Poole, U.K.). Thin-layer chromatography (TLC) plates, precoated with silica gel 60 (without fluorescent indicator) were obtained from Merck (Darmstadt, Germany). All solvents were HPLC grade and were obtained from Fisher Scientific UK, Loughborough, England.

\subsection{Statistical analysis}

All the data are presented as means \pm SD ( $n=3,4$ or 6 as stated). The effects of diet on liver fatty acid composition, hepatic expression of genes of PUFA biosynthesis, and hepatocyte fatty acid desaturation were analyzed by one-way ANOVA, followed where appropriate by Tukey's post test to determine significant differences between individual treatments. Correlations between hepatic expression of desaturase and elongase genes and apparent desaturation and elongation activities in hepatocytes were determined by regression analyses. Percentage data and data which were identified as nonhomogeneous (Bartlett's test) were subjected to either arcsine or log transformation before analysis. Differences were regarded as significant when $\mathrm{P}<0.05$ (Zar, 1984).

\section{Results}

\subsection{Dietary fatty acid compositions}

The control diet (FO), formulated with $100 \%$ FO, contained approximately $20 \%$ total saturates, mainly 16:0, almost $60 \%$ total monounsaturated fatty acids over half of which were the long chain monoenes, 20:1 and 22:1, 5\% n-6 fatty acids predominantly 18:2n-6, and 16\% n-3 fatty acids, predominantly the n-3HUFA, 20:5n-3 and 22:6n-3 in approximately equal amounts, and less than 1\% 18:3n-3 (Table 2). 
Inclusion of graded amounts of LO resulted in graded increased percentages of 18:3n-3, 18:2n-6 and 18:1n-9 with concomitant decreased proportions of n-3HUFA, 16:0, total saturates, 20:1, 22:1 and total monoenes. Thus, in the diet formulated with 100\% LO (LO100), the levels of 18:3n-3 and 18:2n-6 had risen to $50 \%$ and $15 \%$ of total fatty acids, respectively, whereas $20: 5 n-3$ and 22:6n-3 totaled only $2.5 \%$, and total saturates and monoenes were reduced to $10 \%$ and $21 \%$, respectively (Table 2).

\subsection{Effects of diet on liver fatty acid compositions}

After feeding the experimental diets for 20 weeks, liver total lipid from fish fed the control FO diet contained almost 23\% saturates, 40\% monoenes and 38\% PUFA, predominantly the n-3HUFA, 22:6n$3(20 \%)$ and 20:5n-3 (9\%) (Table 3). Increasing dietary LO content was reflected in the liver fatty acid compositions with graded increased percentages of 18:3n-3 and 18:2n-6 and decreased proportions of n-3HUFA, total saturates and total monoenes. In addition, however, there were increased proportions of 18:4n-3, 20:3n-3, 20:4n-3 and 20:2n-6, and decreased proportions of 20:4n-6 and 22:5n-3 (Table 3). Thus after 20 weeks of feeding, the levels of 18:3n-3 and 18:2n-6 in the livers of fish fed diet LO100 had risen to almost $19 \%$ and $9 \%$ of total fatty acids, respectively, whereas 20:5n-3 and 22:6n-3 were reduced to around $4 \%$ and 12\%, respectively. At the end of the trial (40 weeks), the percentage of total PUFA, particularly n-3HUFA, in liver total lipid from fish fed the FO diet was increased at the expense of total monoenes (Table 4). The effects of dietary LO were qualitatively similar to those at 20 weeks, but quantitatively greater with the levels of 18:3n-3 and 18:2n-6 in the livers of fish fed diet LO100 increased to almost $33 \%$ and $12 \%$ of total fatty acids, respectively, whereas $20: 5 n-3$ and $22: 6 n-3$ were reduced to around $3 \%$ and $6 \%$, respectively (Table 4 ).

\subsection{Effects of diet on liver fatty acid desaturase and elongase gene expression}

Measurement of the mRNA abundance by Q-PCR showed that the expression of both the desaturase and elongase genes were increased in a graded manner by increasing inclusion of dietary LO after feeding the diets for 20 weeks. The desaturase transcript copy number (x20), relative to $\beta$-actin expression, was 0.7 in fish fed diet FO and 1.4 in fish fed diet LO100 (Fig. 1A). Similarly, the elongase transcript copy number (x200), relative to $\beta$-actin expression, was 0.9 in fish fed diet FO and 1.9 in fish fed diet LO100 (Fig.1B). Regression analyses showed that the expression of both genes at 20 weeks was positively and negatively correlated with dietary 18:3n-3 and n-3HUFA, respectively, with high significance and $\mathrm{r}^{2}$ values of 0.88 or greater (Table 5). Similar correlations can be derived 
between the expression of the genes and the liver levels of 18:3n-3 and n-3HUFA at 20 weeks (data not shown). However, by the end of the trial after 40 weeks of feeding, there was no significant correlation between dietary or liver 18:3n-3 or n-3HUFA levels and the expression of either gene (Table 5). In both cases, highest expression of the genes was observed in livers from fish fed the LO50 diet and expression of the genes decreased with further increases in dietary LO (Figs.1A and B). Note that, in order to give target gene transcript copy number/ $\beta$-actin transcript copy number ratios in Fig.1. of approximately unity, the transcript copy numbers for the desaturase and elongase were multiplied by 20 and 200, respectively. Therefore, the transcript copy abundance for the desaturase was approximately 8 -fold greater than that for the elongase.

\subsection{Effects of diet on activity of the hepatocyte HUFA biosynthesis pathway}

The activity of the HUFA biosynthesis pathway was measured as the summed radioactivity recovered as desaturated fatty acid products of $\left[1-{ }^{14} \mathrm{C}\right] 18: 3 n-3$ (i.e. 18:4, 20:4, 20:5, $22: 5$ and 22:6). Similarly, by summing their respective products, $\Delta 5$ desaturase (20:5, 22:5 and 22:6) and total elongase (20:4, 20:5, 22:5 and 22:6) activities can be estimated. Mid-way through the feeding trial at 20 weeks, there were clear trends in both the overall activity of the pathway and the total elongation activity, with both generally higher in fish fed diets containing LO compared to activities in fish fed diet FO (Figs.2A and B). Correlations were not significant with $\mathrm{r}^{2}$ values around $0.60-0.63$, and $\mathrm{P}$ values around 0.1 (Table 5). However, by the end of the trial at 40 weeks, the activity of the HUFA biosynthesis pathway was increased in a graded manner in response to increased dietary LO (Fig. 2A), and regression analyses confirmed significant positive and negative correlations with dietary 18:3n-3 and n-3HUFA, with high degrees of confidence $\left(\mathrm{P}<0.001\right.$ and $\left.\mathrm{r}^{2}=0.98 / 0.99\right)$ (Table 5). As with gene expression, similar correlations can be derived between the activity of the HUFA synthesis pathway and liver levels of 18:3n-3 and n-3HUFA at 40 weeks (data not shown). Total fatty acid elongation showed a similar pattern at 40 weeks, increasing with increasing dietary LO (Fig. 2B), and being significantly correlated with dietary 18:3n-3 and n-3HUFA (Table 5). Apparent $\Delta 5$ desaturation activity did not show a clear relationship to dietary LO (Fig. 2C) and was not correlated with dietary 18:3n-3 or n-3HUFA at either sampling point (Table 5).

\section{Discussion}


The results of this study show that the expression of two genes, a fatty acid desaturase and an elongase, involved in the HUFA biosynthetic pathway, was higher in livers of salmon fed diets containing $\mathrm{C}_{18}$ PUFA-rich vegetable oil compared to fish fed diets containing HUFA-rich fish oil. Increased gene expression could, at least in part, account for the higher activity of the HUFA biosynthesis pathway observed previously in fish fed vegetable oils compared to fish fed fish oil (Bell et al., 1997, 2001, 2002; Tocher et al., 1997, 2000, 2001a,b, 2002).

The expression of both $\Delta 5$ desaturase and fatty acid elongase correlated well with both dietary 18:3n-3 and n-3HUFA at 20 weeks, but not after 40 weeks. In contrast, the correlation between dietary fatty acid composition and the activity of the HUFA synthesis pathway including the elongase activity was significant at 40 weeks, but not at 20 weeks. A similar association between hepatocyte HUFA synthesis capacity and dietary fatty acid composition was observed previously. In an earlier trial, the correlations between the activity of the HUFA biosynthetic pathway and dietary $18: 3 n-3$, total $\mathrm{C}_{18}$ PUFA and n-3HUFA levels were highly significant after 50 weeks of feeding the experimental diets, but in an earlier sampling at 32 weeks, there was either no correlation (dietary 18:3n-3, total $\mathrm{C}_{18}$ PUFA) or the significance level of the correlation was reduced (n-3HUFA) (Tocher et al., 2003). That correlations between dietary fatty acid composition and biochemical responses become more significant with feeding periods of longer duration is quite logical. In addition, that tissue gene expression and the activity of the associated enzymes were not similarly correlated with dietary fatty acid composition is not necessarily contradictory when all the interacting factors are considered. Altered dietary fatty acid composition possibly directly affects gene expression as well as tissue fatty acid composition. The changes in gene expression will lead to altered activity of the HUFA biosynthetic pathway, that will also result in changes in tissue fatty acid composition. Altered tissue fatty acid composition, including altered levels of key intermediates such as 18:4n-3 and 20:4n-3, may have feedback effects on enzyme activities that will contribute to overall activity of the pathway. A fuller understanding of all the mechanisms involved in the regulation of desaturase and elongase enzyme activities is required, but, when the complexity of this system is appreciated, dissociation between gene expression and enzyme activity can be understood.

Although $\Delta 6$ desaturase is regarded as the main rate limiting step in the HUFA biosynthesis pathway in mammals, $\Delta 5$ desaturase is reported to also be under nutritional regulation (Brenner, 1981). Consistent with this, $\Delta 5$ desaturase expression was highly correlated with dietary fatty acid composition at 20 weeks in the present trial. However, in contrast to the activities of the fatty acid elongase and the entire HUFA synthesis pathway, the $\Delta 5$ desaturase activity was not correlated with dietary or tissue n-3HUFA or 18:3n-3 at either 20 or 40 weeks. There are possible explanations for 
this result. The HUFA biosynthesis assay measures the activity of the entire pathway and, as such, gives a good estimate of the overall activity or flux through the pathway. In addition, by summing individual products, some estimate can be made of the relative activities of different steps in the pathway. However, it must be appreciated that each individual step is dependent upon the activities of both the preceding (substrate provision) and subsequent (product removal) enzymatic steps and so can only give an indication of relative activities or importance. The position of $\Delta 5$ desaturase, in the middle of the pathway, perhaps contributes to the observed result where it's activity was not correlated with dietary levels of either 18:3n-3 (the pathway substrate) or n-3HUFA (pathway products). Furthermore, the $\Delta 5$ desaturase operates at only one step (conversion of $20: 4 n-3$ to $20: 5 n-3$ ) in the pathway, whereas the elongase can operate at all elongation steps in the pathway (Hastings et al., 2004). Therefore, it is perhaps not surprising that the elongase activity more closely paralleled the overall activity of the pathway.

That the expression and activity of the elongase could be correlated to dietary fatty acid composition and, therefore, was likely to be under nutritional regulation was particularly interesting. Fatty acid elongation is a microsomal process effected in four steps, each catalysed by a specific enzyme. The first step is a condensation reaction of the precursor fatty acyl chain with malonyl-CoA to produce a $\beta$-ketoacyl chain that is subsequently hydrogenated in three successive steps. This first condensation step determines the substrate specificity and is the rate-limiting step of the process and is therefore regarded as being the actual "elongase" enzyme-effected step (Cinti et al., 1992). Previous work on the regulation of the HUFA biosynthesis pathway has tended to focus on the desaturase enzymes as the points of regulation (Brenner, 1981). The present trial gives the best evidence to date that elongase enzymes can also be under nutritional control. In earlier studies with cell cultures we showed that overall HUFA biosynthetic capacity can be greatly affected by the activity of elongase enzymes. Specifically, the inability to synthesise 20:5n-3 and 22:6n-3 in turbot (TF) cells was shown to be primarily due to a deficiency in $\mathrm{C}_{18-20}$ elongase (Ghioni et al., 1999). In addition, the biosynthesis of arachidonic acid from 18:2n-6 in the filamentous fungus Mortierella alpina appears to be ratelimited by the activity of the $\mathrm{C}_{18-20}$ elongase (Wynne and Ratledge, 2000).

As mentioned above, more is known about the modulation of fatty acid desaturase mRNA levels in response to dietary fatty acids. Thus, in mice fed $10 \%$ corn oil, a diet rich in 18:2n-6, the mRNA abundance and hepatic $\Delta 6$ desaturase activity were, respectively, $50 \%$ and $70 \%$ lower than those in mice fed 10\% triolein (18:1n-9), an EFA-deficient diet (Cho et al., 1999a). The levels of hepatic mRNA for both $\Delta 6$ and $\Delta 5$ desaturases in rats fed either $10 \%$ safflower oil (18:2n-6) or menhaden oil (n-3HUFA) were only $25 \%$ of those in rats fed a fat-free diet or a diet containing triolein (Cho et al., 
1999b). Similar studies in fish showed that the transcript of a putative $\Delta 6$ desaturase cloned from sea bream was highly expressed in livers from fish fed a HUFA-free diet and only slightly expressed in livers from fish fed a HUFA-rich diet (Seiliez et al., 2003). Increased desaturase transcript level in fish in response to a vegetable oil diet has also been reported previously, with the liver transcript level of a putative $\Delta 6$ desaturase cloned from rainbow trout being higher in trout fed linseed oil compared to trout fed fish oil (Seiliez et al., 2001). However, desaturase activity was not determined in any of these trials. In our previous trials we have shown that replacing fish oil with vegetable oils resulted in increased activity of the HUFA biosynthetic pathway in isolated hepatocytes from a variety of fish species including trout and salmon (Bell et al., 1997, 2001, 2002; Tocher et al., 1997, 2000, 2001a,b, 2002). To our knowledge, the present study is the first to report both gene expression and enzyme activities in an investigation of the nutritional regulation of the HUFA biosynthetic pathway.

In previous studies it has not been possible to establish the mechanisms underpinning the differential activity of the HUFA biosynthetic pathway in response to dietary fatty acid composition. The evidence supported the hypothesis that the activity of the pathway could be influenced by the levels of both substrate (18:3n-3) and product (n-3HUFA) fatty acid levels in the diet. The present study indicates that transcriptional control of fatty acid desaturase and elongase gene expression is one mechanism whereby dietary fatty acids could influence the activity of the HUFA biosynthetic pathway in fish. Further studies are required to determine whether gene expression is controlled positively by substrate or negatively by product, or both. PUFA can potentially affect gene transcription by a number of direct and indirect mechanisms including changes in membrane composition, eicosanoid production, oxidant stress, nuclear receptor activation or covalent modification of specific transcription factors (Jump et al., 1999). Specifically, PUFA are known to bind and directly influence the activities of a variety of transcription factors including members of the nuclear hormone receptor family, peroxisome proliferator activated receptors (PPARs), which in turn have been shown to be regulators of many genes involved in lipid homeostatic processes (Jump, 2002). PPAR genes have been identified in fish including Atlantic salmon and plaice (Ruyter et al., 1997; Leaver et al., 1998). A number of studies have suggested that fatty acid desaturases are regulated by PPARs in mammals, for example stearoyl CoA $\Delta 9$ desaturase genes have been shown to be directly regulated by PPARs by virtue of peroxisome proliferator response elements (PPREs) in their upstream regulatory regions. In addition, in rodents peroxisomal proliferators are known to up-regulate fatty acyl $\Delta 6, \Delta 5$ and $\Delta 9$ desaturases (Kawashima et al., 1990; Gronn et al., 1992; Alegret et al., 1995) and clofibrate has been shown to increase the desaturation of 20:5n-3 in rainbow trout (Tocher and Sargent, 1993). However, this does 
not exclude the possibility that fatty acids may also influence fatty acid desaturation and elongation more directly at a membrane level through alterations in fluidity or membrane microenvironments.

\section{Acknowledgements}

This work and XZ were supported by the European Union (Researching alternatives to fish oils in aquaculture, RAFOA, QLRT-2000-30058) as part of the Fifth Framework Programme.

\section{References}

Ackman, R.G., 1980. Fish lipids, part 1. In: Connell, J.J. (Ed.) Advances in Fish Science and Technology. Fishing News Books, Farnham, U.K. pp. 87-103.

Agaba, M., Tocher, D.R., Dickson, C., Dick, J.R., Teale, A.J., 2003. A zebrafish cDNA encoding a multifunctional enzyme involved in the elongation of polyunsaturated, monounsaturated and saturated fatty acids. Mar. Biotechnol., in press.

Aki, T. Shimada, Y., Inagaki, K., Higashimoto, H., Kawamoto, S., Shiget, S., Ono, K., Suzuki, O., 1999. Molecular cloning and functional characterisation of rat $\Delta 6$ fatty acid desaturase. Biochem. Biophys. Res. Commun. 255, 575 -579.

Alegret, M., Cerqueda, E. Ferramdo, R., Vazquez, M., Sanchez, R.M., Adzet, T., Merlos, M., Laguna, J.C., 1995. Selective modification of rat hepatic microsomal fatty acid chain elongation and desaturation by fibrates: relationship with peroxisomal proliferation. Br. J. Pharmacol. 114, 13511358.

Barlow, S., 2000. Fishmeal and oil: sustainable feed ingredients for aquafeeds. Global Aquacult. Advocate 4, 85-88.

Beaudoin, F, Michaelson, L.V., Hey, SJ., Lewis, M.L., Shewry, P.R., Sayanova, O., Napier, J.A., 2000. Heterologous expression in yeast of the polyunsaturated fatty acid biosynthetic pathway. Proc. Natl. Acad. Sci. USA 97, $6421-6426$.

Bell, J.G., McEvoy, J., Tocher, D.R., McGhee, F., Campbell, P.J., Sargent, J.R., 2001. Replacement of fish oil with rape seed oil in diets of Atlantic salmon (Salmo salar) affects tissue lipid compositions and hepatocyte fatty acid metabolism. J. Nutr. 131, 1535-1543.

Bell, J.G., Henderson, R.J., Tocher, D.R., McGhee, F., Dick, J.R., Porter, A., Smullen, R., Sargent, J.R., 2002. Substituting fish oil with crude palm oil in the diet of Atlantic salmon (Salmo salar) affects tissue fatty acid compositions and hepatic fatty acid metabolism. J. Nutr.132, 222-230. 
Bell, J.G., Tocher, D.R., Farndale, B.M., Cox, D.I., McKinney, R.W., Sargent, J.R., 1997. The effect of dietary lipid on polyunsaturated fatty acid metabolism in Atlantic salmon (Salmo salar) undergoing parr-smolt transformation. Lipids 32, 515-525.

Brenner, R.R., 1981. Nutritional and hormonal factors influencing desaturation of essential fatty acids. Prog. Lipid Res. 20, 41-47.

Cho, H. P., Nakamura, M.T., Clarke, S.D., 1999a. Cloning, expression, and nutritional regulation of the mammalian $\Delta-6$ desaturase. J. Biol. Chem. 274, 471-477.

Cho, H. P., Nakamura, M.T., Clarke, S.D., 1999b. Cloning, expression, and fatty acid regulation of the human $\Delta-5$ desaturase. J. Biol. Chem. 274, 37335-37339.

Christie, W.W., 1982. Lipid Analysis, 2nd Edition. Pergamon Press, Oxford. p. 207.

Cinti, D.L., Cook, L., Nagi, M.N., Suneja, S.K., 1992. The fatty acid elongation system of mammalian endplasmic reticulum. Prog. Lipid Res. 31, 1-51.

Folch, J., Lees, M., Sloane-Stanley, G.H., 1957. A simple method for the isolation and purification of total lipids from animal tissues. J. Biol. Chem. 226, 497-509.

Ghioni, C., Tocher, D.R., Sargent, J.R., 1997. The effect of culture on morphology, lipid and fatty acid composition, and polyunsaturated fatty acid metabolism of rainbow trout (Oncorhynchus mykiss) skin cells. Fish Physiol. Biochem. 16, 499-513.

Ghioni, C., Tocher, D.R., Bell, M.V., Dick, J.R., Sargent, J.R., 1999. Low $\mathrm{C}_{18}$ to $\mathrm{C}_{20}$ fatty acid elongase activity and limited conversion of stearidonic acid, 18:4n-3, to eicosapentaenoic acid, 20:5n-3, in a cell line from the turbot, Scophthalmus maximus. Biochim. Biophys. Acta, 1437, 179-181.

Grønn, M., Christensen, E., Hagve, T. -A., Christophersen, B.O., 1992. Effects of clofibrate feeding on essential fatty acid desaturation and oxidation in isolated rat liver cells. Biochim. Biophys. Acta $1123,170-176$.

Hastings, N, Agaba, M, Tocher, D.R., Leaver, M.J., Dick, J.R., Sargent, J.R., Teale, A.J., 2001. A vertebrate fatty acid desaturase with $\Delta 5$ and $\Delta 6$ activities. Proc. Natl. Acad. Sci. USA 98, 1430414309.

Hastings, N., Agaba, M.K., Zheng, X., Tocher, D.R., Dick, J.R., Dickson, C., Teale, A.J., 2004. Molecular cloning and functional characterization of fatty acyl desaturase and elongase cDNAs involved in the production of eicosapentaenoic and docosahexanoic acids from $\alpha$-linolenic acid in Atlantic salmon (Salmo salar). Mar. Biotechnol., in press.

Inagaki, K., Aki, T., Fukuda, Y., Kawamoto, S., Shigeta, S., Ono, K., Suzuki, O., 2002. Identification and expression of a rat fatty acid elongase involved the biosynthesis of C18 fatty acids. Biosci. Biotechnol. Biochem. 66, 613-621. 
Jump, D. B., 2002. The biochemistry of n-3 polyunsaturated fatty acids. J. Biol. Chem. 277, 87558758.

Jump, D. B., Thelen, A., Ren, B., Mater, M., 1999. Multiple mechanisms for polyunsaturated fatty acid regulation of hepatic gene transcription. Prostaglandins Leukotrienes Essent. Fatty Acids 60, 345349.

Kawashima, Y., Musoh, K., Kozuka, H., 1990. Peroxisome proliferators enhance linoleic acid meatbolism in rat liver. Increased biosynthesis of $\omega 6$ polyunsaturated fatty acids. J. Biol. Chem. 265, 9170-9175.

Leaver, M. J., Wright, J., George, S.G., 1998. A peroxisome proliferator activated receptor gene from the marine flatfish, the plaice (Pleuronectes platessa). Mar. Env. Res. 46, 75-79.

Leonard, A.E., Kelder, B., Bobik, E.G., Kroeger, P.E., Chuang, L-T., Thurmond, J.M., Parker-Barnes, J.M., Kopchick, J.J., Huang, Y.-S., Murkerji, P., 2000a. cDNA cloning and characterisation of human $\Delta 5$ desaturase involved in the synthesis of arachidonic acid. Biochem. J. 347, 719-724.

Leonard, A.E., Bobik, E.G., Dorado, J., Kroeger, P.E., Chuang, L.-T., Thurmond, J.M., Parker-Barnes, J.M., Das, T., Huang Y.-S., Murkerji, P., 2000b. Cloning of a human cDNA encoding a novel enzyme involved in the elongation of long chain polyunsaturated fatty acids. Biochem. J., 350, $765-770$.

Lowry, O.H., Rosebrough, N.J., Farr, A.L., Randall, R.J., 1951. Protein measurement with the folin phenol reagent. J. Biol. Chem. 193, 265-275.

Michaelson, L.V., Napier, J.A., Lewis, M., Griffiths, G., Lazarus, C.M., Stobart, A.K., 1998. Functional identification of a fatty acid $\Delta^{5}$ desaturase gene from Caenorhabditis elegans. FEBS Lett. 439, 215-218.

Napier, J.A., Hey, S.J., Lacey, D.J., Shewry, P.R., 1998. Identification of a Caenorhabditis elegans $\Delta 6$ fatty acid-desaturase by heterologous expression in Saccharomyces cereviciae. Biochem. J. $330,611-614$.

National Research Council, 1993. Nutrient Requirements of Fish, National Academy Press, Washington D.C.

Parker - Barnes, J.M., Das,T., Bobik, E., Leonard, A.E., Thurmond, J.M., Chuang, L., Huang, Y.S., Mukerji, P., 2000. Identification and characterization of an enzyme involved in the elongation of n-6 and n-3 polyunsaturated fatty acid. Proc. Natl. Acad. Sci. USA 97, 8284 - 8289.

Ruyter, B. Andersen, O., Dehli, A., Ostlund Farrants, A.-K., Gjoen, T., Thomassen, M.S., 1997. Peroxisome proliferator activated receptors in Atlantic salmon (Salmo salar): effects on PPAR 
transcription and acyl-CoA oxidase activity in hepatocytes by peroxisome proliferators and fatty acids. Biochim. Biophys. Acta 1348, 331-338.

Sargent J.R., Tacon, A., 1999. Development of farmed fish: a nutritionally necessary alternative to meat. Proc. Nutr. Soc. 58, 377-383.

Sargent, J.R., Bell, J.G., Bell, M.V., Henderson, R.J., Tocher, D.R., 1995. Requirement criteria for essential fatty acids. J. Appl. Ichthyol. 11, 183-198.

Sargent, J.R., Bell, J.G., McEvoy, L., Tocher, D.R., Estevez, A., 1999. Recent developments in the essential fatty acid nutrition of fish. Aquaculture 177, 191-199.

Sargent, J. R., Tocher, D. R., Bell, J. G., 2002. The lipids. In:Halver, J.E., Hardy, R.W. (Eds.) Fish Nutrition, Academic Press, San Diego, CA pp. 181-257.

Seiliez, I., Panseat, S., Kaushik, S., Bergot, P., 2001. Cloning, tissue distribution and nutritional regulation of a $\Delta 6$-desaturase-like enzyme in rainbow trout. Comp. Biochem. Physiol.130B, 83-93.

Seiliez, I., Panseat, S., Corraze, G., Kaushik, S., Bergot, P., 2003. Cloning and nutritional regulation of a $\Delta 6$-desaturase-like enzyme in the marine teleost gilthead seabream (Sparus aurata). Comp. Biochem. Physiol.135B, 449-460.

Tidwell, J.H., Allan, G.L., 2002. Fish as food:aquaculture's contribution. World Aquaculture 33, 4448.

Tocher, D.R., Harvie, D.G., 1988. Fatty acid compositions of the major phosphoglycerides from fish neural tissues : (n-3) and (n-6) polyunsaturated fatty acids in rainbow trout (Salmo gairdneri, L.) and cod (Gadus morhua) brains and retinas. Fish Physiol. Biochem. 5, 229-239.

Tocher, D.R., Sargent, J.R., 1993. No relationship between morphology changes and metabolism of $\alpha$-linolenate and eicosapentaenoate in rainbow trout (Oncorhynchus mykiss) astroglial cells in primary culture. Comp. Biochem. Physiol. 106C, 211-219.

Tocher, D.R., Sargent, J.R., Frerichs, G.N., 1988. The fatty acid compositions of established fish cell lines after long-term culture in mammalian sera. Fish Physiol. Biochem. 5, 219-227.

Tocher, D.R., Bell, J.G., Sargent, J.R. 1996. Induction of $\Delta 9$-fatty acyl desaturation in rainbow trout (Oncorhynchus mykiss) liver by dietary manipulation. Comp. Biochem. Physiol. 113B, 205-212.

Tocher, D.R., Bell, J.G., Dick, J.R., Sargent, J.R., 1997. Fatty acyl desaturation in isolated hepatocytes from Atlantic salmon (Salmo salar): Stimulation by dietary borage oil containing $\gamma$ linolenic acid. Lipids 32, 1237-1247.

Tocher, D.R., Leaver, M.J., Hodgson, P.A., 1998. Recent advances in the biochemistry and molecular biology of fatty acyl desaturases. Prog. Lipid Res. 37, 73-117.

Tocher, D.R., Bell, J.G., Henderson, R.J., McGhee, F., Mitchell, D., Morris, P.C., 2000. The effect 
of dietary linseed and rapeseed oils on polyunsaturated fatty acid metabolism in Atlantic salmon (Salmo salar) undergoing parr-smolt transformation. Fish. Physiol. Biochem. 23, 59-73.

Tocher, D.R., Bell, J.G., MacGlaughlin, P., McGhee, F., Dick, J.R. 2001a. Hepatocyte fatty acid desaturation and polyunsaturated fatty acid composition of liver in salmonids: Effects of dietary vegetable oil. Comp. Biochem Physiol. 130, 257-270.

Tocher, D. R., Agaba, M., Hastings, N., Bell, J. G., Dick, J. R., Teale, A. J., 2001b. Nutritional regulation of hepatocyte fatty acid desaturation and polyunsaturated fatty acid composition in zebrafish (Danio rerio) and tilapia (Oreochromis nilotica). Fish Physiol. Biochem. 24, 309-320.

Tocher, D. R., Fonseca-Madrigal, J., Bell, J. G., Dick, J. R., Henderson, R. J., Sargent, J. R., 2002. Effects of diets containing linseed oil on fatty acid desaturation and oxidation in hepatocytes and intestinal enterocytes in Atlantic salmon (Salmo salar). Fish Physiol. Biochem. 26, 157-170.

Tocher, D. R., Bell, J. G., Dick, J. R., Crampton, V.O., 2003. Effects of vegetable oil diets on Atlantic salmon hepatocyte desaturase activities and liver fatty acid compositions. Lipids 38, 723-732.

Watts, J.L., Browse, J., 1999. Isolation and characterisation of a $\Delta 5$ fatty acid desaturase from Caenorhabditis elegans. Arch. Biochem. Biophys. 362, 175-182.

Wilson, R., Sargent, J.R., 1992. High resolution separation of polyunsaturated fatty acids by argentation thin-layer chromatography. J. Chromatogr. 623, 403-407.

Wynn, J.P., Ratledge, C., 2000. Evidence that the rate limiting step for the biosynthesis of arachidonic acid in Mortierella alpina is at the level of the 18:3 to 20:3 elongase. Microbiology 146, 23252331.

Zar, J.H., 1984. Biostatistical Analysis, 2nd Edition. Prentice-Hall, Englewood Cliffs. 
Legends to Figures:

Fig. 1. Effect of feeding dietary linseed oil for 20 and 40 weeks on the expression of fatty acid $\Delta 5$ desaturase (A) and elongase (B) genes in Atlantic salmon liver. Transcript (mRNA) copy number was determined by real-time quantitative PCR (Q-PCR) as described in the Materials and Methods Section. Results are expressed as the ratio of copy numbers between the target gene and $\beta$-actin, regarded as a "house-keeping" gene of constant expression and are means \pm S.D. $(n=4)$. Specifically for desaturase the units are copy number x 20/copy number of $\beta$-actin and for elongase the units are copy number $\mathrm{x}$ $200 /$ copy number of $\beta$-actin. Different superscript letters indicate significant differences $(P<0.05)$ for relative copy number of a particular gene at each sampling point (20 or 40 weeks) in livers from fish fed different diets as determined by one-way ANOVA followed, where appropriate, by Tukey's comparison test. FO, fish oil; LO, linseed oil.

Fig. 2. Effect of feeding dietary linseed oil for 20 and 40 weeks on the overall activity of the entire HUFA biosynthetic pathway (A), total elongation activity (B) and apparent $\Delta 5$ desaturation activity (C) in isolated hepatocytes from Atlantic salmon. Results are means \pm S.D. $(n=4)$ and represent the rate of conversion (pmol.h $\mathrm{h}^{-1} \mathrm{mg}$ protein ${ }^{-1}$ ) of $\left[1-{ }^{14} \mathrm{C}\right] 18: 3 \mathrm{n}-3$ to (A) all desaturated products (sum of radioactivity recovered as 18:4n-3, 20:4n-3, 20:5n-3, 22:5n-3 and 22:6n-3), (B) all elongated products (sum of radioactivity recovered as $20: 4 n-3,20: 5 n-3,22: 5 n-3$ and 22:6n-3), and (C) $\Delta 5$ desaturated products (sum of radioactivity recovered as 20:5n-3, 22:5n-3 and 22:6n-3). Different superscript letters indicate significant differences $(\mathrm{P}<0.05)$ for particular activities at each sampling point $(20$ or 40 weeks) in hepatocytes from fish fed different diets as determined by one-way ANOVA followed, where appropriate, by Tukey's comparison test. FO, fish oil; LO, linseed oil.

[N.B. NOTE FOR REFEREES (NOT FOR PUBLICATION) In converting to PDF format for the review process, the $Y$ axis labels were lost. They are present in the originals!

Fig.1A \& B - Relative copy number

Fig2A $-\left[1-{ }^{14} \mathrm{C}\right] 18: 3 \mathrm{n}-3$ converted (pmol/h/mg protein)

Fig2B - Elongated products formed (pmol/h/mg protein)

Fig.2C $-\Delta 5$ desaturated products formed (pmol/h/mg protein)

Also small problem with micro symbol in $M$ \& $M$ so replaced with u for review] 
Table 1. Formulation $(\mathrm{g} / \mathrm{kg})$ and proximate composition (\% of weight of feed) of diets containing graded levels of linseed oil.

\begin{tabular}{lccccc}
\hline Component & FO & LO25 & LO50 & LO75 & LO100 \\
\hline Fishmeal $^{1}$ & 338 & 338 & 338 & 338 & 338 \\
Maize gluten $^{2}$ & 200 & 200 & 200 & 200 & 200 \\
Soya (Hi Pro) $^{3}$ & 100 & 100 & 100 & 100 & 100 \\
Fish oil $^{4}$ & 258 & 193.5 & 129 & 64.5 & 0 \\
Linseed oil $^{5}$ & 0 & 64.5 & 129 & 193.5 & 258 \\
Micronutrients $^{6}$ & 25 & 25 & 25 & 25 & 25 \\
Composition & & & & & \\
\cline { 1 - 2 } Protein & 44.1 & 44.1 & 44.2 & 44.4 & 43.6 \\
Lipid & 28.9 & 28.9 & 30.2 & 29.5 & 31.1 \\
Ash & 6.5 & 6.9 & 7.2 & 7.5 & 7.6 \\
Moisture & 5.9 & 6.3 & 5.7 & 6.1 & 5.6 \\
\hline
\end{tabular}

${ }^{1}$ Scandinavian LT-fish meal (Nordsildmel, Norway).

${ }^{2}$ Cargill/ADM, Decatur, Illinois.

${ }^{3}$ Soybean meal (Denofa, Fredrikstad, Norway).

${ }^{4}$ Capelin oil (Nordsildmel, Norway) supplemented with 200 ppm BHT.

${ }^{5}$ Crude E.C.C. linseed oil (N.V. Oliefabriek Lictervelde, Belgium) supplemented with 500ppm Ronoxan A (Roche, Switzerland).

${ }^{6}$ Vitamin, mineral and carotenoid pigment premix formulated to Nutreco specification (Farmix, Trouw Nutrition, TheNetherlands). 
Table 2. Fatty acid compositions (\% of total fatty acids by weight) of diets containing graded levels of linseed oil.

\begin{tabular}{|c|c|c|c|c|c|}
\hline & $\mathrm{FO}$ & $\mathrm{LO} 25$ & LO50 & LO75 & LO100 \\
\hline $14: 0$ & 6.3 & 4.7 & 3.4 & 2.0 & 0.4 \\
\hline $16: 0$ & 12.1 & 10.6 & 9.3 & 8.1 & 6.9 \\
\hline 18:0 & 1.1 & 1.7 & 2.1 & 2.7 & 3.1 \\
\hline Total saturates $^{1}$ & 19.9 & 17.2 & 15.1 & 13.0 & 10.5 \\
\hline $16: 1 n-7$ & 8.1 & 6.1 & 4.2 & 2.3 & 0.5 \\
\hline $18: 1 n-9$ & 11.9 & 13.6 & 15.1 & 16.0 & 17.0 \\
\hline $18: 1 n-7$ & 3.3 & 2.6 & 2.2 & 1.6 & 1.0 \\
\hline $20: 1 n-9$ & 17.9 & 13.1 & 9.0 & 5.0 & 1.1 \\
\hline $22: 1 n-11$ & 13.3 & 10.1 & 7.1 & 4.3 & 1.1 \\
\hline $22: 1 n-9$ & 2.1 & 1.5 & 1.0 & 0.5 & 0.1 \\
\hline Total monoenes ${ }^{2}$ & 58.4 & 48.4 & 39.6 & 30.5 & 21.1 \\
\hline $18: 2 n-6$ & 4.2 & 7.4 & 9.8 & 12.3 & 15.1 \\
\hline $20: 4 n-6$ & 0.2 & 0.2 & 0.1 & 0.1 & 0.1 \\
\hline Total n-6PUFA ${ }^{3}$ & 5.0 & 8.0 & 10.2 & 12.6 & 15.2 \\
\hline $18: 3 n-3$ & 0.9 & 14.0 & 25.6 & 37.8 & 50.4 \\
\hline $18: 4 n-3$ & 2.9 & 2.1 & 1.6 & 0.9 & 0.2 \\
\hline $20: 5 n-3$ & 5.9 & 4.6 & 3.5 & 2.2 & 1.0 \\
\hline $22: 6 n-3$ & 5.0 & 4.0 & 3.4 & 2.4 & 1.5 \\
\hline Total n-3PUFA ${ }^{4}$ & 15.7 & 25.6 & 34.6 & 43.7 & 53.3 \\
\hline Total PUFA & 21.7 & 34.4 & 45.3 & 56.5 & 68.5 \\
\hline
\end{tabular}

${ }^{1}$ Totals include $15: 0$, present at up to $0.3 \%{ }^{2}$ Totals include $16: 1 \mathrm{n}-9,20: 1 \mathrm{n}-11$, 20:1n-7 and 24:1, present at up to $0.5 \%$; ${ }^{3}$ Totals include $18: 3 n-6,20: 2 n-6$ and 20:3n-6, present at up to $0.2 \%$; ${ }^{4}$ Totals include $20: 3 n-3,20: 4 n-3$ and $22: 5 n-3$, present at up to $0.4 \%$. FO, fish oil, LO, linseed oil; PUFA, polyunsaturated fatty acids. 
Table 3. Fatty acid compositions (percentage of total fatty acids by weight) of total lipid of liver fror Atlantic salmon (Salmo salar L.) fed the experimental diets for 20 weeks.

\begin{tabular}{|c|c|c|c|c|c|}
\hline & FO & $\mathrm{LO} 25$ & LO50 & LO75 & LO100 \\
\hline Total saturated & $22.7 \pm 1.3^{\mathrm{a}}$ & $20.9 \pm 0.6^{\mathrm{b}}$ & $20.6 \pm 0.9^{b}$ & $18.7 \pm 1.0^{\mathrm{c}}$ & $17.8 \pm 1.1^{\mathrm{c}}$ \\
\hline Total monoenes & $39.8 \pm 3.2^{a}$ & $35.7 \pm 1.7^{\mathrm{b}}$ & $34.5 \pm 1.4^{\mathrm{b}}$ & $30.3 \pm 1.5^{c}$ & $27.4 \pm 1.3^{\mathrm{c}}$ \\
\hline $18: 2 n-6$ & $2.1 \pm 0.1^{\mathrm{e}}$ & $3.7 \pm 0.1 \mathrm{~d}$ & $5.1 \pm 0.2^{c}$ & $6.8 \pm 0.4^{b}$ & $8.5 \pm 0.2^{a}$ \\
\hline $20: 2 n-6$ & $0.5 \pm 0.1^{\mathrm{e}}$ & $0.8 \pm 0.0^{\mathrm{d}}$ & $1.1 \pm 0.1^{c}$ & $1.3 \pm 0.0^{b}$ & $1.5 \pm 0.0^{\mathrm{a}}$ \\
\hline $20: 3 n-6$ & $0.3 \pm 0.1^{\mathrm{b}}$ & $0.3 \pm 0.0^{\mathrm{b}}$ & $0.3 \pm 0.0^{b}$ & $0.4 \pm 0.1$ & $0.5 \pm 0.0^{\mathrm{a}}$ \\
\hline $20: 4 n-6$ & $1.2 \pm 0.1^{\mathrm{a}}$ & $1.1 \pm 0.1 \mathrm{ab}$ & $0.9 \pm 0.0^{b c}$ & $0.8 \pm 0.2^{\mathrm{c}}$ & $0.5 \pm 0.1^{\mathrm{d}}$ \\
\hline $22: 5 n-6$ & $0.2 \pm 0.0^{a}$ & $0.2 \pm 0.0^{\mathrm{a}}$ & $0.1 \pm 0.1^{\mathrm{b}}$ & $0.1 \pm 0.0^{b}$ & $0.1 \pm 0.0^{\mathrm{b}}$ \\
\hline Total n-6 PUFA & $4.3 \pm 0.1^{\mathrm{e}}$ & $6.2 \pm 0.1^{\mathrm{d}}$ & $7.5 \pm 0.3^{c}$ & $9.4 \pm 0.3^{b}$ & $11.2 \pm 0.2^{\mathrm{a}}$ \\
\hline $18: 3 n-3$ & $0.4 \pm 0.1^{\mathrm{e}}$ & $4.5 \pm 0.2^{\mathrm{d}}$ & $8.7 \pm 0.3^{c}$ & $14.1 \pm 1.2^{b}$ & $18.9 \pm 1.0^{\mathrm{a}}$ \\
\hline $18: 4 n-3$ & $0.3 \pm 0.0^{\mathrm{c}}$ & $0.3 \pm 0.0^{\mathrm{c}}$ & $0.3 \pm 0.0^{\mathrm{c}}$ & $0.5 \pm 0.1^{\mathrm{b}}$ & $0.7 \pm 0.0^{\mathrm{a}}$ \\
\hline $20: 3 n-3$ & $0.1 \pm 0.0^{\mathrm{e}}$ & $0.9 \pm 0.1^{\mathrm{d}}$ & $1.8 \pm 0.0^{\mathrm{c}}$ & $2.7 \pm 0.2^{b}$ & $3.6 \pm 0.3^{\mathrm{a}}$ \\
\hline $20: 4 n-3$ & $1.2 \pm 0.1^{\mathrm{e}}$ & $1.4 \pm 0.1^{\mathrm{d}}$ & $1.6 \pm 0.1^{\mathrm{c}}$ & $2.0 \pm 0.1$ & $2.6 \pm 0.1^{\mathrm{a}}$ \\
\hline $20: 5 n-3$ & $8.6 \pm 0.6^{a}$ & $8.0 \pm 0.5^{a}$ & $7.0 \pm 0.4^{\mathrm{b}}$ & $5.5 \pm 0.2^{c}$ & $4.4 \pm 0.3^{\mathrm{d}}$ \\
\hline $22: 5 n-3$ & $2.6 \pm 0.1^{\mathrm{a}}$ & $2.4 \pm 0.2^{a}$ & $1.9 \pm 0.1^{\mathrm{b}}$ & $1.7 \pm 0.1^{\mathrm{b}}$ & $1.4 \pm 0.1^{\mathrm{c}}$ \\
\hline $22: 6 n-3$ & $20.0 \pm 1.4^{\mathrm{a}}$ & $19.6 \pm 1.0^{\mathrm{a}}$ & $16.1 \pm 0.7^{\mathrm{b}}$ & $15.1 \pm 1.9^{b}$ & $12.0 \pm 1.1^{c}$ \\
\hline Total n-3 PUFA & $33.2 \pm 2.0^{\mathrm{c}}$ & $37.1 \pm 1.4^{b}$ & $37.4 \pm 0.7^{b}$ & $41.7 \pm 1.1^{a}$ & $43.6 \pm 0.4^{a}$ \\
\hline Total PUFA & $37.5 \pm 1.9^{\mathrm{d}}$ & $43.3 \pm 1.4^{\mathrm{c}}$ & $44.9 \pm 0.6 \mathrm{c}$ & $51.1 \pm 1.0^{\mathrm{b}}$ & $54.8 \pm 0.4^{\mathrm{a}}$ \\
\hline
\end{tabular}

Results are means \pm SD $(n=6)$. FO, fish oil; LO, linseed oil; PUFA, polyunsaturated fatty acids. 
Table 4. Fatty acid compositions (percentage of total fatty acids by weight) of total lipid of liver from Atlantic salmon (Salmo salar L.) fed the experimental diets for 40 weeks.

\begin{tabular}{|c|c|c|c|c|c|}
\hline & FO & $\mathrm{LO} 25$ & LO50 & LO75 & LO100 \\
\hline Total saturated & $24.1 \pm 1.2^{a}$ & $21.3 \pm 1.8^{b}$ & $19.3 \pm 1.0^{b}$ & $17.0 \pm 1.1^{c}$ & $12.7 \pm 1.0^{\mathrm{d}}$ \\
\hline Total monoenes & $30.2 \pm 3.1^{a}$ & $31.1 \pm 1.9^{\mathrm{a}}$ & $26.4 \pm 3.0^{b}$ & $24.5 \pm 1.9^{b}$ & $23.9 \pm 2.9$ \\
\hline $18: 2 n-6$ & $2.6 \pm 0.1^{\mathrm{e}}$ & $4.4 \pm 0.1^{\mathrm{d}}$ & $6.0 \pm 0.3^{c}$ & $8.0 \pm 0.2^{b}$ & $11.6 \pm 0.6^{\mathrm{a}}$ \\
\hline $20: 2 n-6$ & $0.4 \pm 0.1^{\mathrm{d}}$ & $0.6 \pm 0.1^{c}$ & $0.7 \pm 0.1^{c}$ & $0.9 \pm 0.1^{\mathrm{b}}$ & $1.1 \pm 0.1$ \\
\hline $20: 3 n-6$ & $0.3 \pm 0.0^{\mathrm{b}}$ & $0.3 \pm 0.0^{b}$ & $0.3 \pm 0.0^{b}$ & $0.4 \pm 0.1^{\mathrm{a}}$ & $0.3 \pm 0.0$ \\
\hline $20: 4 n-6$ & $1.4 \pm 0.1^{\mathrm{a}}$ & $1.1 \pm 0.1^{b}$ & $0.9 \pm 0.1^{\mathrm{c}}$ & $0.7 \pm 0.1^{\mathrm{d}}$ & $0.3 \pm 0.1^{\mathrm{e}}$ \\
\hline $22: 5 n-6$ & $0.2 \pm 0.1^{a}$ & $0.1 \pm 0.0^{b}$ & $0.1 \pm 0.0^{b}$ & $0.1 \pm 0.0^{\mathrm{b}}$ & $0.0 \pm 0.0$ \\
\hline Total n-6 PUFA & $4.9 \pm 0.2^{\mathrm{e}}$ & $6.6 \pm 0.2^{d}$ & $8.0 \pm 0.3^{c}$ & $10.0 \pm 0.2^{\mathrm{b}}$ & $13.3 \pm 0.7^{a}$ \\
\hline $18: 3 n-3$ & $0.5 \pm 0.2^{\mathrm{e}}$ & $6.8 \pm 0.5^{\mathrm{d}}$ & $14.4 \pm 0.6^{\mathrm{c}}$ & $20.3 \pm 1.1^{b}$ & $32.6 \pm 1.2$ \\
\hline $18: 4 n-3$ & $0.4 \pm 0.1^{\mathrm{c}}$ & $0.4 \pm 0.1^{\mathrm{c}}$ & $0.5 \pm 0.1^{\mathrm{c}}$ & $0.8 \pm 0.2^{\mathrm{b}}$ & $1.1 \pm 0.2^{\mathrm{a}}$ \\
\hline $20: 3 n-3$ & $0.1 \pm 0.0^{\mathrm{e}}$ & $0.8 \pm 0.1^{\mathrm{d}}$ & $1.6 \pm 0.2^{\mathrm{c}}$ & $2.5 \pm 0.2^{b}$ & $3.8 \pm 0.4^{\mathrm{a}}$ \\
\hline $20: 4 n-3$ & $1.6 \pm 0.1^{\mathrm{c}}$ & $1.9 \pm 0.1^{\mathrm{c}}$ & $2.4 \pm 0.2^{b}$ & $3.0 \pm 0.1^{\mathrm{a}}$ & $3.1 \pm 0.4^{a}$ \\
\hline $20: 5 n-3$ & $10.0 \pm 0.4^{a}$ & $8.5 \pm 0.5^{b}$ & $7.6 \pm 0.7^{b c}$ & $6.4 \pm 0.8^{c}$ & $3.1 \pm 1.1$ \\
\hline $22: 5 n-3$ & $3.7 \pm 0.4^{\mathrm{a}}$ & $2.8 \pm 0.2^{b}$ & $2.3 \pm 0.3^{c}$ & $1.6 \pm 0.1^{\mathrm{d}}$ & $0.8 \pm 0.3$ \\
\hline $22: 6 n-3$ & $24.4 \pm 1.6^{\mathrm{a}}$ & $19.7 \pm 1.5^{\mathrm{b}}$ & $17.2 \pm 1.7^{b}$ & $13.7 \pm 1.4^{\mathrm{c}}$ & $5.6 \pm 1.6$ \\
\hline Total n-3 PUFA & $40.6 \pm 2.1^{c}$ & $40.8 \pm 2.0^{\mathrm{c}}$ & $46.0 \pm 2.4^{b}$ & $48.3 \pm 1.1^{\mathrm{ab}}$ & $50.0 \pm 3.3$ \\
\hline Total PUFA & $45.7 \pm 2.0^{\mathrm{d}}$ & $47.6 \pm 1.9^{\mathrm{d}}$ & $54.3 \pm 2.2^{c}$ & $58.5 \pm 0.9^{b}$ & $63.4 \pm 2.6$ \\
\hline
\end{tabular}

Results are means \pm SD $(n=6)$. FO, fish oil; LO, linseed oil; PUFA, polyunsaturated fatty acids. 
Table 5. Correlation (regression) analyses $\left(\mathrm{r}^{2}\right.$, slope values and significance) for dietary fatty acids (18:3n-3 and n-3HUFA) versus hepatocyte desaturase and elongase gene expression and HUFA biosynthetic activities.

\begin{tabular}{|c|c|c|c|c|c|c|}
\hline \multirow[b]{2}{*}{ Fatty acid } & \multicolumn{3}{|c|}{20 weeks } & \multicolumn{3}{|c|}{40 weeks } \\
\hline & $r^{2}$ & slope & significance & $r^{2}$ & slope & significance \\
\hline \multicolumn{7}{|l|}{ Dietary $18: 3 n-3$} \\
\hline$\Delta 5$ gene expression & 0.95 & $0.015 \pm 0.002$ & 0.004 & 0.06 & $0.004 \pm 0.009$ & 0.695 \\
\hline Elongase gene expression & 0.89 & $0.023 \pm 0.005$ & 0.015 & 0.11 & $0.008 \pm 0.013$ & 0.591 \\
\hline Combined gene expression & 0.95 & $0.038 \pm 0.005$ & 0.005 & 0.09 & $0.012 \pm 0.022$ & 0.629 \\
\hline Entire pathway activity & 0.61 & $0.061 \pm 0.031$ & 0.121 & 0.98 & $0.051 \pm 0.004$ & 0.001 \\
\hline$\Delta 5$ desaturation activity & 0.22 & $0.012 \pm 0.013$ & 0.428 & 0.08 & $0.002 \pm 0.004$ & 0.278 \\
\hline Elongation activity & 0.60 & $0.062 \pm 0.029$ & 0.126 & 0.99 & $0.034 \pm 0.002$ & 0.001 \\
\hline \multicolumn{7}{|l|}{ Dietary n-3HUFA } \\
\hline$\Delta 5$ gene expression & 0.96 & $-0.087 \pm 0.010$ & 0.003 & 0.05 & $-0.021 \pm 0.056$ & 0.731 \\
\hline Elongase gene expression & 0.88 & $-0.014 \pm 0.029$ & 0.018 & 0.09 & $-0.042 \pm 0.076$ & 0.620 \\
\hline Combined gene expression & 0.95 & $-0.224 \pm 0.031$ & 0.005 & 0.07 & $-0.063 \pm 0.130$ & 0.662 \\
\hline Entire pathway activity & 0.63 & $-0.402 \pm 0.178$ & 0.109 & 0.99 & $-0.302 \pm 0.021$ & 0.001 \\
\hline$\Delta 5$ desaturation activity & 0.23 & $-0.070 \pm 0.074$ & 0.414 & 0.07 & $-0.011 \pm 0.022$ & 0.667 \\
\hline Elongation activity & 0.62 & $-0.369 \pm 0.168$ & 0.115 & 0.99 & $-0.198 \pm 0.012$ & 0.0004 \\
\hline
\end{tabular}

HUFA, highly unsaturated fatty acid. 
Fig.1.

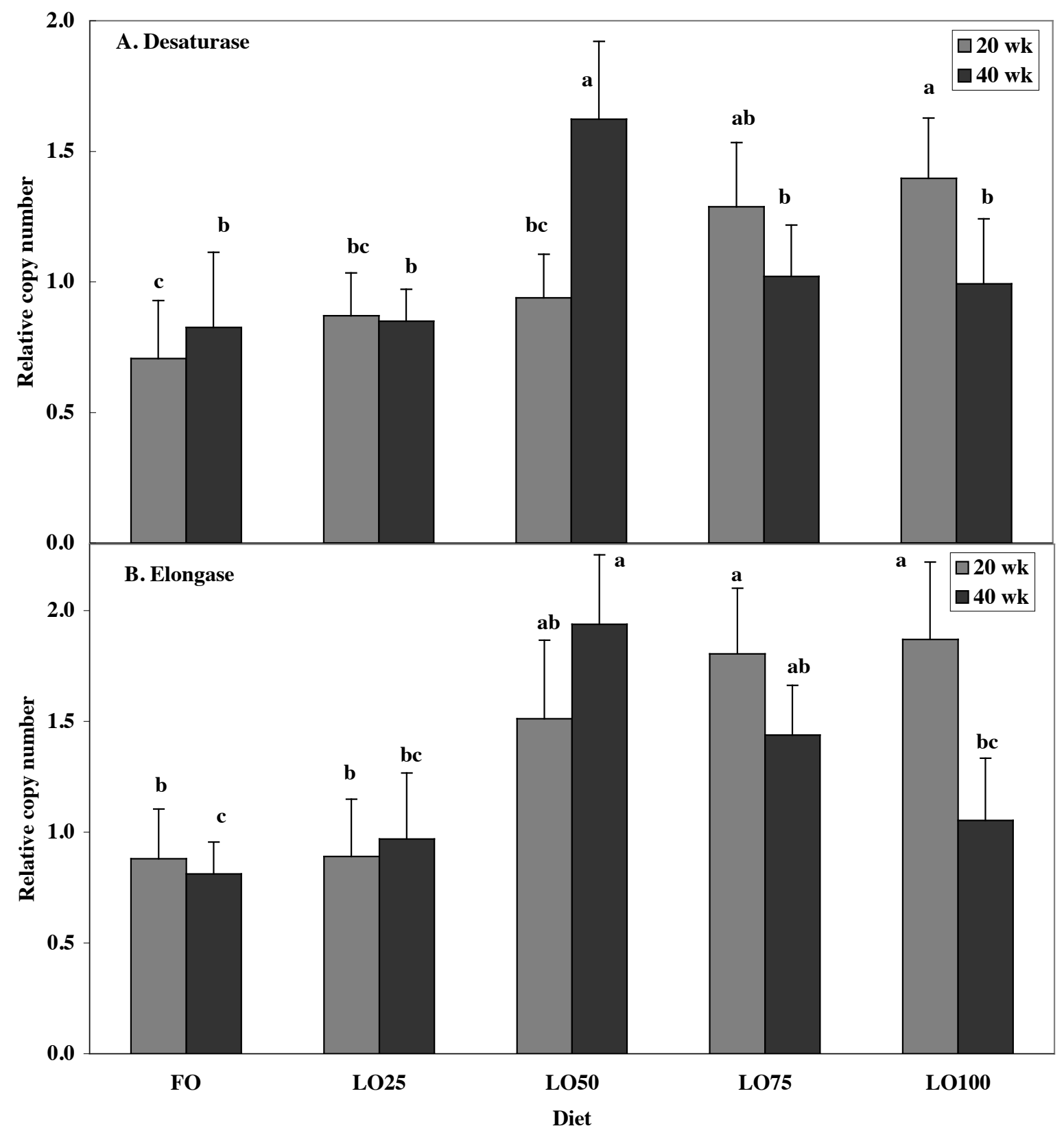


Fig.2.

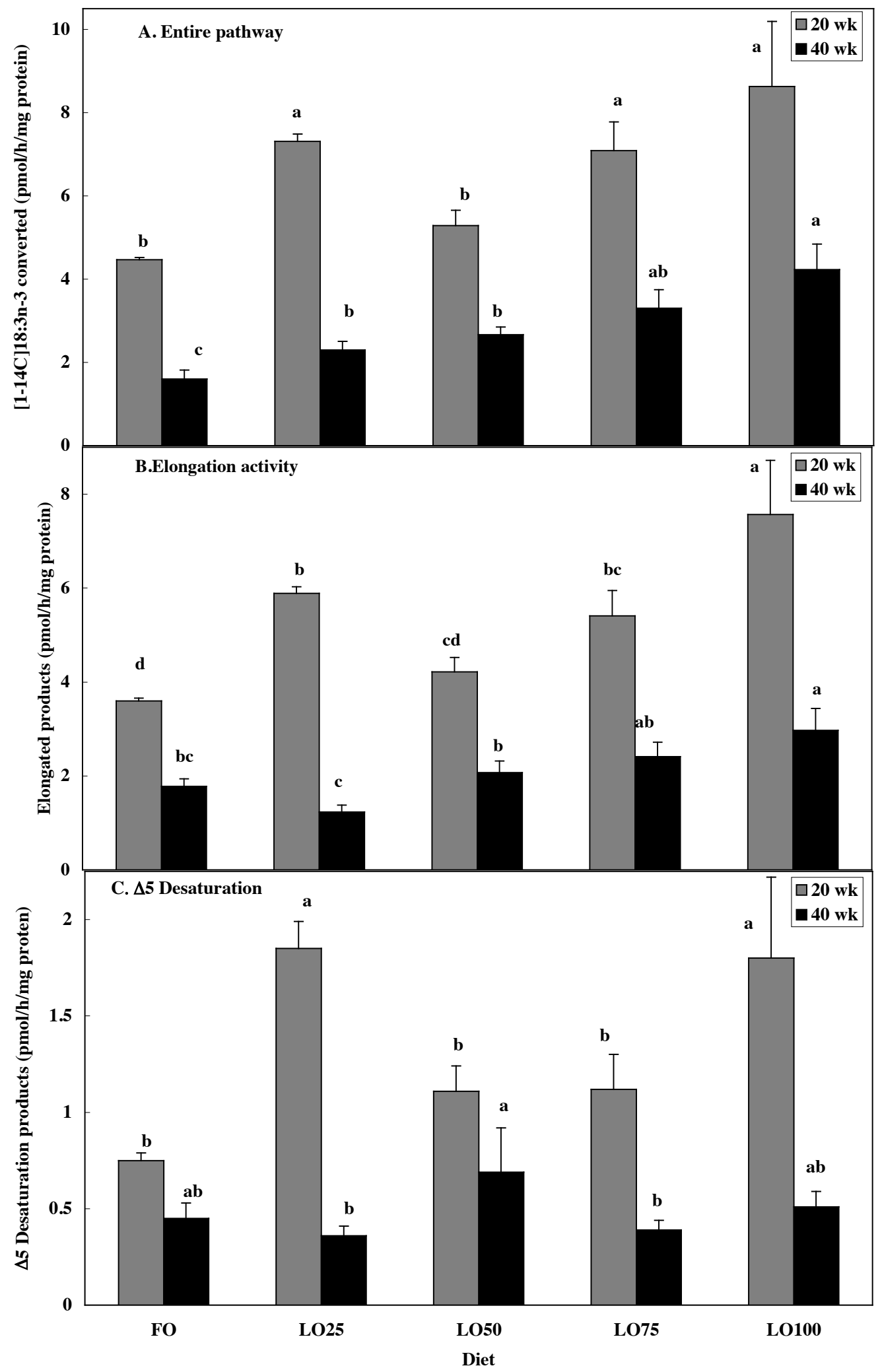

